\title{
Análisis del color en el Álbum llustrado. Un valor añadido constructor de sentidos
}

Miriam Peña miriam.peza@gmail.com

EHU/UPV, España

Reference

Peña, Miriam; (2012) "Análisis del color en el Álbum Ilustrado. Un valor añadido constructor de sentidos", p. 193-197 . In: Barbosa, Helena; Quental, Joana [Eds]. Proceedings of the 2nd International Conference of Art, Illustration and Visual Culture in Infant and Primary Education. São Paulo: Blucher, 2015. ISSN 2318-695X, ISBN: 978-989-98185-0-7 DOI 10.5151/edupro-aivcipe-37

Mediante esta reflexión es nuestra intención indagar entorno a la idea de la importancia del color en el Álbum Ilustrado. El color, entendido más allá de un mero juego formal con funciones decorativas que concluyan en ilustraciones efectistas carentes de significados

Entendemos el cromatismo aplicado al Álbum Ilustrado como una dimensión emotiva añadida y constructora de sentidos. La aplicación del color debe de ser capaz de aportar nuevos códigos que refuercen la historia a narrar. Planteamos como eje del análisis que la información cromática adquirida tenga la capacidad de aportar nuevos significados; valores añadidos a los que el lenguaje escrito hablado no tiene acceso en alguno de los casos.

Palabras clave Álbum ilustrado, cromatismo, construcción de significados.

Abstract

Through this reflection is our intention to investigate around the idea of the importance of color in Picture Books. The color, understood beyond a formal game working as decorative illustrations full of effects and without any meaningful message. We understand the color applied to Picture Books as an emotional dimension and as a tool to understand different meanings. The application of color must be able to bring new values that reinforce the story to tell. We propose the idea that the color information acquired has the ability to bring new meanings; values added where the written or spoken language do not have access in many cases.

picture books, use of color, meaning construction.

\section{El cromatismo creador de significados}

En el libro De lo espiritual en el Arte, Kandinsky podemos encontrar esta reflexión sobre la capacidad cognitiva del color, "E igual que la sensación física del hielo frío, si penetra más adentro despierta sensaciones más profundas y puede provocar toda una serie de vivencias psicológicas, así la impresión superficial del color se puede convertir en vivencia." (Kandinsky, 1996:51)

Mediante este ejemplo entendemos que el conocimiento del color se puede adquirir mediante vivencias y asociaciones de ideas que hacemos a partir de esas experiencias. De este modo, podríamos decir que la contemplación del color - u otros fenómenos- dan pie a la asociación de ideas y en consecuencia a la creación de sentidos propios.

No debemos olvidar que la aplicación de un color no depende unicamente de sus propias características, si no que existen otros muchos parámetros que pueden reforzar o debilitar su intención inicial. 
$2^{\text {nd }}$ International Conference Art, Illustration and Visual Culture in Infant and Primary Education $2^{\circ}$ Congreso Internacional Arte, Ilustración y Cultura Visual en Educación Infantil y Primaria
${ }^{\circ}$ Congresso Internacional de Arte, llustração e Cultura Visual na Educação Infantil e Primária

\section{Análisis de un álbum ilustrado}

\subsection{Les voisins musiciens}

Figuras 1 y 2. A la izquierda: Cubierta álbum ilustrado. A derecha: Guardas álbum ilustrado. Shibuda, J., "Les voisins musiciens" Edit. Autrement (2011).

Figura 3. Shibuda, J., "Les voisins musiciens" Edit. Autrement (2011). \|lustración en álbum ilustrado.
Aspectos como saturación, tonalidad, recursos gráficos aplicados, forma con la que se compone, soporte sobre el que se trabaja, composición espacial o la conbinación con otros colores, etc. ejercerán un papel primordial en la emisión del concepto a transmitir.

Con la intención de ejemplificar las ideas mencionadas anteriormente, analizaremos varios trabajos en los que la utilización específica del color sea una pieza esencial en el conjunto de la obra. Ilustraciones en las que esa específica aplicación cromática haya reforzado el mensaje de la historia a narrar, convirtiendose así en llave para adquirir una comprensión más completa.
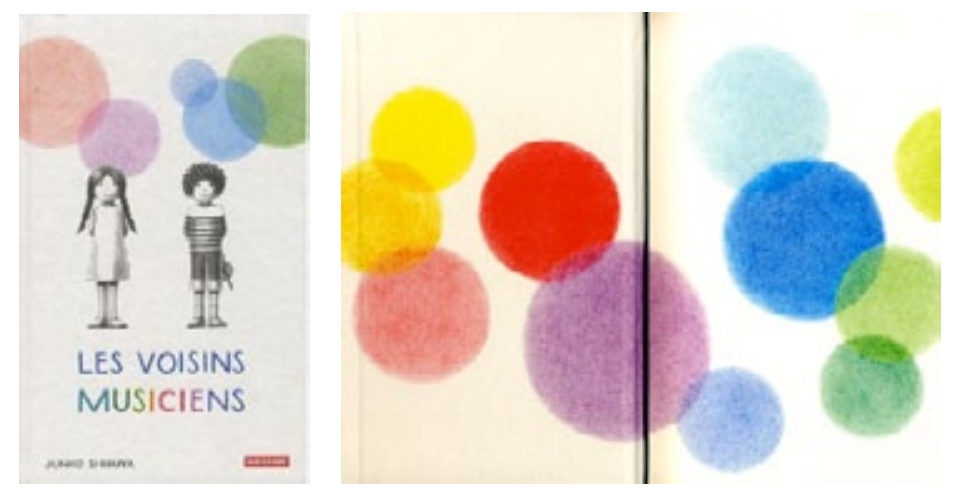

Les Voisins musiciens de Junco Shibuya, es un gran ejemplo donde se evidencia la importancia del color en la construcción de significados. A pesar de ser una obra carente de texto y diagramación lineal, el color se convierte en pieza esencial de la lectura visual, donde sin él, carecería de sentido.

A lo largo de la lectura, la utilización del color como mediador visual, consigue hacer analogías con la música, es más, nos da a entender que un instrumento musical suena desafinado o que es capaz de hacer asociaciones con conceptos abstractos como la armonia.

Del mismo modo y sin leer una sola palabra, el lector llega a discernir las sensaciones de los protagonistas. Sensaciones como complicidad, o tranquilidad se dejan entrever a través de una lectura silenciosa.

Referente a los aspectos gráficos, la composición es sencilla, en blanco y negro con un grafismo resuelto con ciertos matices knife debido a que está coloreado con pinturas de madera, tradicionalmente asociadas a la etapa escolar.

Situados en un escenario que se sucece una página tras otra (figura3), el autor nos presenta dos ventanas enfrentadas en las que nada acontece que manera llamativa.

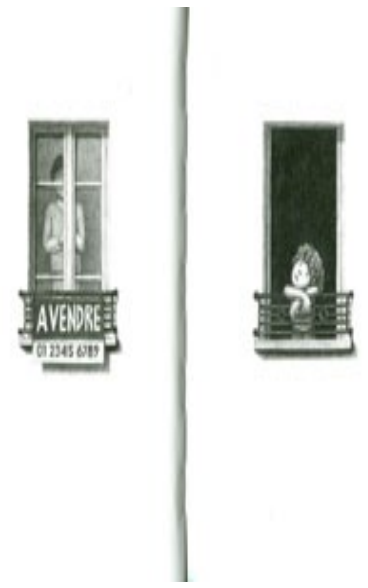


$2^{\text {nd }}$ International Conference

Art, Illustration and Visual Culture

in Infant and Primary Education $2^{\circ}$ Congreso Internacional

Arte, llustración y Cultura Visual en Educación Infantil y Primaria $2^{\circ}$ Congresso Internacional

de Arte, Ilustração e Cultura Visual

na Educação Infantil e Primária
Figuras 4, 5 y 6 . Shibuda, J., "Les voisins musiciens" Edit. Autrement (2011). \|lustración en álbum ilustrado.
Figuras 7,8 y 9 . Shibuda, J., "Les voisins musiciens" Edit. Autrement (2011). llustración en álbum ilustrado.

Figura 10. Shibuda, J., "Les voisins musiciens" Edit. Autrement (2011). Ilustración en álbum ilustrado.
Una mancha verde captura la atención del lector. La representación del sonido mediante colores cálidos y un grafismo radial ayuda a crear asociaciones de ideas, llegando a entender la representación del sonido como si de una onomatopeya cromática se tratase.
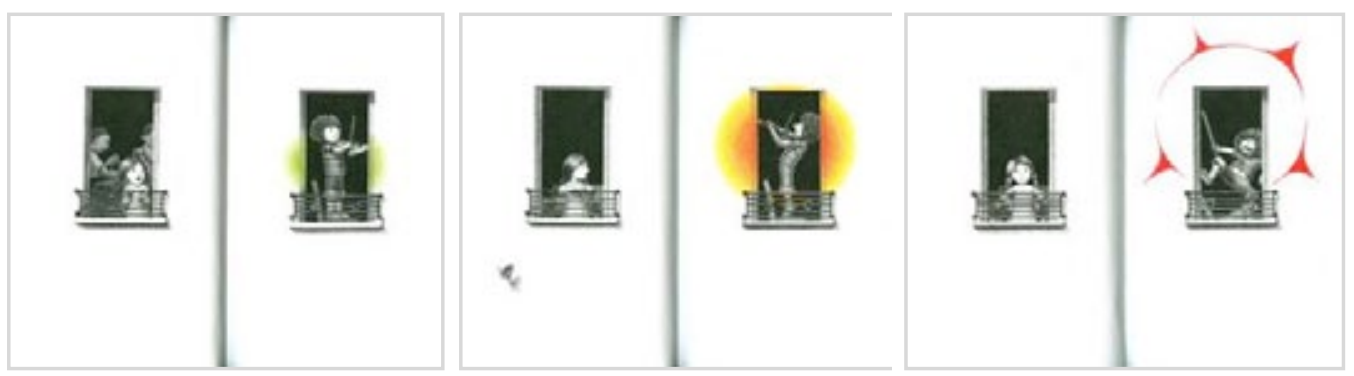

En las escenas posteriores se plantea una melodía diferente. La aportación de cada músico va creciendo hasta el punto de fusionarse uno con el otro y ensamblarse.
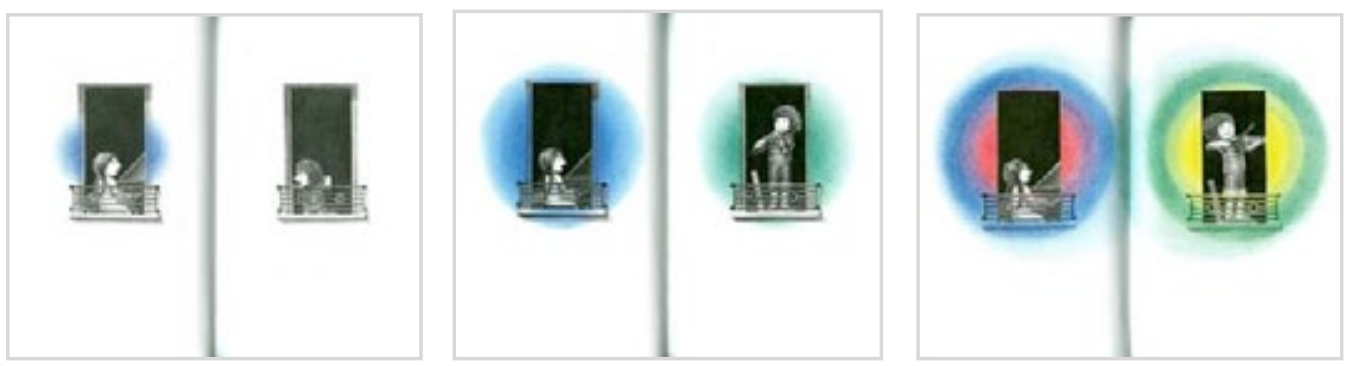

A modo de desenlace se plantea un escenario imaginario, los colores sa han transformado en sensación o lugar en el cual el lector se transporta a un concierto casi real.

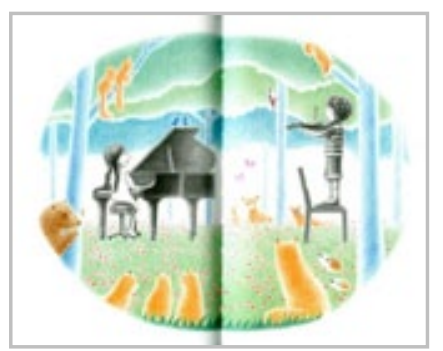

Para el segundo ejemplo hemos elegido un álbum ilustrado de la extensa obra de Anthony Browne, donde el cromatismo de la imagen narra lo que no dice la palabra, y en contraposición, la palabra aporta datos no mencionados icónicamente.

Sumergido en un mundo entre lo real y lo irreal, el uso del color se convierte en una herramienta esencial en la construcción de significados.

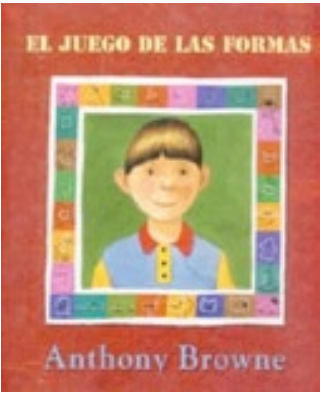


2nd International Conference Art, Illustration and Visual Culture in Infant and Primary Education $2^{\circ}$ Congreso Internacional

Arte, llustración y Cultura Visual en Educación Infantil y Primaria
Congresso Internacional

de Arte, llustração e Cultura Visual

na Educação Infantil e Primária
Figuras 12 y 13. Browne, A., "El juego de las formas" Edit. FCE (2004). llustración en álbum ilustrado.
Figura 14. Figuras 12 y 13. Browne, A., "El juego de las formas" Edit. FCE (2004). Ilustración en álbum ilustrado.
Esta lectura nos habla de una familia que va a pasar un día en el museo. En las figuras 12 y 13 se pueden apreciar la primera y la última escena. Con la intención de dar entender el descontento de alguno de los miembros de la familia hacia el plan propuesto, el autor hace uso de la tonalidad, planteando una escena casi monocroma.

En contraposición, el camino de vuelta se representa saturado y lleno de luz haciendo una analogía con un sentimiento de felicidad.
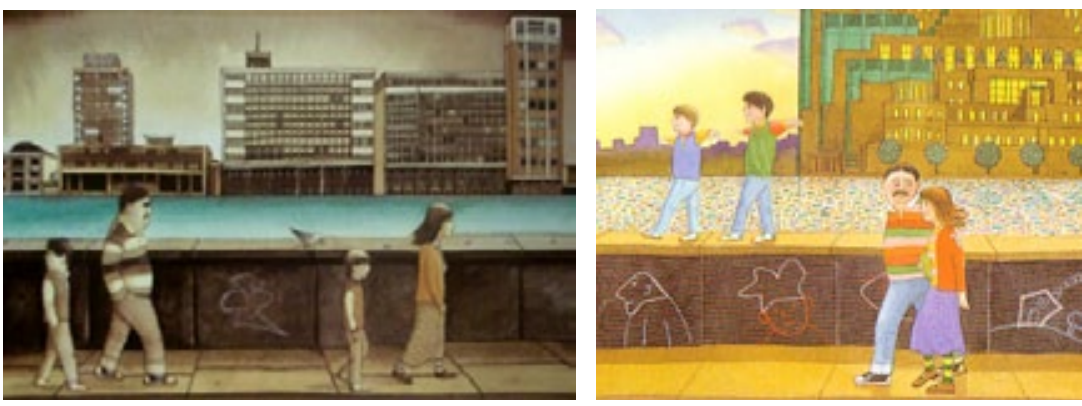

Hemos elegido la siguiente imagen por la sutileza en la que se aplica la simbología del color.

La manga del niño aparece aparentemente coloreada de rojo. Esta imagen representa la transición entre el descontento que mostraba inicialmente por ir tener que ir al museo y la posibilidad de interesarse por lo que acontece en el cuadro.

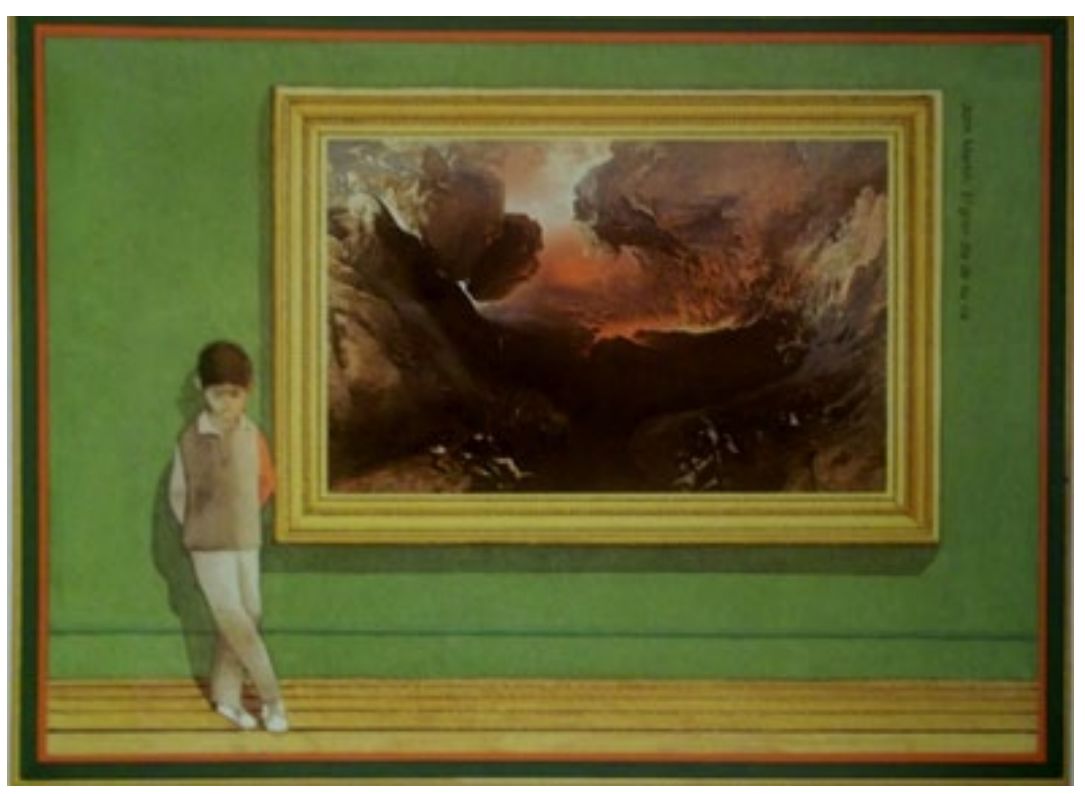

A modo de conclusión, creemos en la capacidad del Álbum llustrado como medio de educación hacia una sensibilidad cromática donde el color puede marcar la diferencia en la forma de comunicar el mensaje. Esta habilidad no debería subestimarse y sería recomendable que alcanzase el nivel de importancia que tiene el texto escrito, en lugar de estar relegado a este.

Para llegar a comprender estas metáforas visuales, se requieren ciertas habilidades lectoras más allá de una lectura lineal del texto. Es por esto que resulta esencial una adecuada sinergia entre todos los componentes que constituyen la obra, el narrador del álbum ilustrado debe así ampliar su visión hacia el pensamiento visual. De este modo llegará a entender los significados expresivos del color como parte constructiva de significados en el desarrollo intelectual del niño. 
$2^{\circ}$ Congreso Internacional

Arte, Ilustración y Cultura Visual en Educación Infantil y Primaria 2ongresso Internacional

de Arte, Ilustracão e Cultura Visual

na Educação Infantil e Primária

\section{Referencias}

Arnheim, R.: (1969).Visual Thinking. Traducido al castellano por Fernando Inglés Bonilla. Barcelona: Ediciones Paidos Ibérica (1998).

Arnheim, R.: (1989). Thoughts on Art Education. Traducido al castellano por Rubén Masera. Barcelona: Ediciones Paidos Ibérica (1993).

Browne, A, J.: (2011). Jugar el juego de las formas. Santiago de Chile: FCE.

Costa, J., Moles, A.: (1991). Imagen didáctica. Barcelona: Ceac.

Duran, T.: (2009). Álbumes y otras lecturas. Barcelona: Octaedro.

Hernandez, F.: (2000). Educación y cultura visual. Barcelona: Ediciones octaedro.

Moreno, V.: (2003). Leer con los cinco sentidos. Pamplona: Pamiela.

Kandisnky, V::(1996). Del lo espiritual en el arte. Barcelona:Paídos.

\section{Referencias en línea:}

Sipe, L.: Comoresponden los niños a los álbumes ilustrados: cinco tipos de comprensión lectora [en linea] [Consulta 15 mayo 2012]. Disponible en, http://literatura.gretel.cat/sites/default/files/conferencia_ sipe_o.pdf

\section{De los álbumes utilizados:}

Shibuya, J.: (2011). Les voisins musiciens. Paris: Autrement.

Browne, A.: (2004). El juego de las formas. Méjico: FCE. 